\title{
Hamsa
}

Journal of Judaic and Islamic Studies

\section{L'anthroponymie des chrétiens arabisés de la péninsule Ibérique médiévale : le double nom des " mozarabes ", IXe-XIIIe siècles}

Jean-Pierre Molénat

\section{(2) OpenEdition}

Journals

Édition électronique

URL : https://journals.openedition.org/hamsa/742

DOI : $10.4000 /$ hamsa.742

ISSN : 2183-2633

Éditeur

CIDEHUS - Centro Interdisciplinar de História Culturas e Sociedades da Universidade de Évora

Référence électronique

Jean-Pierre Molénat, «L'anthroponymie des chrétiens arabisés de la péninsule Ibérique médiévale : le double nom des « mozarabes ", IXe-XIIIe siècles », Hamsa [En ligne], 3 | 2017, mis en ligne le 31 mars 2017, consulté le 13 mai 2021. URL : http://journals.openedition.org/hamsa/742 ; DOI : https:// doi.org/10.4000/hamsa.742

\section{(c) $\underset{\mathrm{EY}}{(\mathrm{NQ} \mathrm{NO}}$}

Hamsa est mise à disposition selon les termes de la Licence Creative Commons Attribution - Pas d'Utilisation Commerciale - Pas de Modification 4.0 International. 


\title{
L'anthroponymie des chrétiens arabisés de la péninsule Ibérique médiévale : le double nom des «mozarabes», IXe-XIIle siècles
}

\author{
Jean-Pierre Molénat \\ Directeur de Recherche émérite CNRS \\ Institut de Recherche et d'Histoire des Textes (IRHT), Paris
}

\begin{abstract}
Resumo:
Nas três etapas da sua existência na Península Ibérica medieval, os cristãos arabizados, tradicionalmente denominados "moçárabes", caraterizam-se pelo fenómeno do duplo nome, árabe e latino-cristão, seja no al-Andalus omíada e taifal (sécs. IX-XI), nos reinos cristãos do Norte, principalmente no de Leão (sécs. IX-XI) ou, finalmente, na Toledo da pretensa Reconquista (sécs. XII-XIII). Este fenómeno nasce, evidentemente, na Córdova omíada, apesar da rarefação das fontes disponíveis a este respeito (quer árabes, quer latinas, cada uma delas empregando o sistema correspondente à língua utilizada). Afirma-se plenamente em Leão, com a abundância de nomes árabes (e não "arabizados"), combinados com os de origem cristã, latina ou gótica, na profusão documental disponível, que não deixa dúvidas quanto à presença de uma população cristã "arabizada", qualquer que seja a sua controversa origem. Enfim, e paradoxalmente, sobrevive e afirma-se na documentação árabe dos "moçárabes" da Toledo cristã. Este fenómeno não pode ser considerado senão como a marca de uma dupla cultura daqueles que são portadores dessa dualidade onomástica.
\end{abstract}

Palavras-chave: Moçárabes, cristãos arabizados, Córdova, Leão, Toledo, ism ‘alam, nisba, kunya

\section{Résumé :}

Aux trois étapes de leur existence dans la Péninsule Ibérique médiévale, les chrétiens arabisés, traditionnellement appelés «mozarabes», sont caractérisés par le phénomène du double nom, arabe et latino-chrétien, soit en al-Andalus omeyyade et taïfale (VIIIe-Xle siècles), dans les royaumes chrétiens du Nord, principalement celui de León (IXe-Xle siècles), et enfin dans la Tolède de la prétendue Reconquista (XIIe-XIIle siècle). II prend évidemment naissance dans la Cordoue omeyyade, malgré la rareté des sources disponibles à cet égard (soit arabes, soit latines, chacune employant le système correspondant à la langue utilisée). Il s'affirme pleinement en León, avec l'abondance des noms arabes (et non pas "arabisés"), combinés avec ceux d'origine chrétienne, latine ou gothique, dans l'abondante documentation disponible, qui ne laisse pas de place au doute quant à la présence d'une population chrétienne "arabisée", quelle que soit son origine controversée. Enfin, et paradoxalement, il survit et s'affirme dans la documentation arabe des "mozarabes" de la Tolède chrétienne. Ce phénomène ne peut être considérée que comme la marque de la double culture de ceux qui sont les porteurs de cette dualité onomastique.

Mots-clés : Mozarabes, chrétiens arabisés, Cordoue, León, Tolède, ism ‘alam, nisba, kunya

Pour étudier l'anthroponymie des chrétiens arabisés de la péninsule Ibérique, il conviendra de distinguer trois étapes spatio-temporelles dans l'histoire de ceux que l'on a coutume de dénommer «mozarabes», un terme de nos jours largement remis en question ${ }^{1}$, et qu'il serait

1 La première remise en question du terme se trouve, à notre connaissance, dans les articles de Richard 
préférable, dans toute la mesure du possible, de remplacer par celui de "chrétiens arabisés» ${ }^{2}$, expression que celui qui reste, jusqu'à aujourd'hui, leur classique historien, Francisco Javier Simonet évitait soigneusement, dans la seconde moitié du XIXe siècle ${ }^{3}$, parce qu'elle se trouve en contradiction fondamentale avec la base même de sa théorie qui présentait les "mozarabes» comme les résistants contre l'islamisation et à l'arabisation.

Le premier moment de leur histoire correspond à l'étape que l'on a le plus souvent en vue, lorsque l'on parle de mozarabes, celle du séjour comme une minorité, sinon de point de vue numérique, mais tout au moins du point de vue du statut social de dimmī-s, partagé avec la minorité juive, à l'intérieur d'une al-Andalus islamique gouvernée par les émirs, puis califes, omeyyades de Cordoue, et ensuite par leurs successeurs, les princes, surnommés les rois de taïfas (mulūk al-țawā'if).

La seconde étape qui se trouve être, en partie seulement, contemporaine de la première, est celle du séjour dans les états chrétiens du nord de la péninsule, avec la question de savoir si les personnes qui y apparaissent comme «arabisés», en tant que porteurs de noms partiellement au moins arabes, sont des immigrés, venus, eux-mêmes ou leurs ascendants, des terres islamiques d'al-Andalus, ou s'ils se sont «arabisés», au moins en ce qui concerne leurs noms, sur place.

L'ultime étape qu'il conviendra de distinguer sera celle de «la fin des chrétiens arabisés d'alAndalus ${ }^{4}$, durant laquelle les mozarabes de Tolède, puisqu'il s'agit désormais exclusivement de ceux-ci, qu'ils aient été indigènes dans la ville, ou réfugiés arrivés du Sud encore islamique, en fuite notamment devant l'arrivée des Almohades, conservèrent pendant plus de deux cents ans, jusqu'au début du XIVe siècle, l'usage oral et écrit de la langue arabe, comme l'attestent notamment les quelque 1.200 documents rédigés dans la langue du ḍād à Tolède entre 1085 et les dernières années du XIIle siècle ${ }^{5}$, documents dont il convient de relever que s'ils sont arabes dans la forme, c'est à dire par l'écriture, la langue et les formulaires utilisés, ils restent néanmoins conformes à la loi wisigothique dans leur contenu ${ }^{6}$.

Hitchcock: "El supuesto mozarabismo andaluz», in Andalucía Medieval. Actas del I Congreso de Historia de Andalucía (Córdoba, diciembre de 1976), Cordoue, Publicaciones del Monte de Piedad y Caja de Ahorros, 1978, t. 1, p. 149-151, et «¿Quienes fueron los verdaderos mozárabes? Una contribución a la historia del mozarabismo», Nueva Revista de Filología Hispánica 30/2 (1981), p. 574-585.

2 A l'inverse, Henri Bresc et Annliese Nef ont apliqué le terme «mozarabes» aux chrétiens arabisés de Sicile ("Les mozarabes de Sicile (1100-1300)», in Cavalieri alla conquista del Sud-Studi sull'Italia normanna in memoria di Léon-Robert Ménager, éd. E. Cuozzo et J.-M. Martin, Bari, Editori Laterza, 1998, p. 134-156. 3 Historia de los mozárabes de España deducida de los mejores y más auténticos testimonios de los escritores cristianos y árabes, Madrid, Real Academia de la Historia, 1897-1903. On sait que la rédaction de cette œuvre a été bien antérieure à sa publication. D'autre part, il en existe plusieurs réimpressions datant de la seconde moitié du XXe siècle, ce qui prouve, sinon son actualité, du moins l'usage qui continue d'en être fait jusqu'à aujourd'hui.

4 J.-P Molénat, «La fin des chrétiens arabisés d'al-Andalus. Mozarabes de Tolède et du Gharb au XIle siècle», in, ¿Existe una identidad mozárabe? Historia, lengua y cultura de los cristianos de al-Andalus (ss. IX-XII), éd. C. Aillet, M. Penelas et Ph. Roisse, Madrid, Casa de Velázquez, 2008, p. 287-297.

${ }^{5}$ Ces documents ont été en majeure partie publiés et partiellement traduits par l'érudit arabisant espagnol Ángel González Palencia, sous le titre: Los mozárabes de Toledo en los siglos XII y XIII, 4 vol., Madrid, Instituto de Valencia de Don Juan, 1926-1930. Nous renverrons à cette publication sous les formes: MT suivi du numéro du document, et MT-VP, suivi de la page, pour le "volume préliminaire", le dernier publié.

6 J.-P. Molénat, «Peut-on trouver trace de la Loi islamique dans les documents arabes chrétiens de Tolède des XIle et XIIle siècles?», communication présentée au colloque international tenu, sous la direction de Christian Müller, au Centre Jacques Berque de Rabat (Maroc), les 13-15 novembre 2013: «Rethinking Classical Islamic Law: Can Fiqh be Aplied Law?», à paraître dans Medievalista online. 


\section{L'étape omeyyade et taïfale.}

Durant cette période, les noms des chrétiens, tels du moins qu'ils apparaissent dans la documentation, et principalement leurs écrits en langue latine correspondant à la crise des "martyrs de Cordoue», au milieu du Xe siècle, sont des noms "chrétiens», qu'ils soient d'origine hébraïque, latine ou germanique, mais sous une forme latine. On trouve ainsi les noms d'Eulogius, Paulus Albarus, Samson parmi les exaltés contre le régime islamique, mais également au nombre de ceux qui surent s'acommoder de la domination arabe et collaborèrent avec elle, comme l'évêque de Malaga, Hostegesis, le comte des mozarabes de Cordoue, Servandus ${ }^{7}$, ou l'évêque d'lliberis, Samuel ${ }^{8}$, ou bien encore de ceux dont on ignore la position à cet égard, tels le poète Ciprianus ${ }^{9}$. II a été ainsi possible d'établir une liste des noms latins des chrétiens d'alAndalus de la seconde moitié du IXe siècle, tels qu'ils apparaissent dans les écrits latins des mozarabes ${ }^{10}$. Les noms mixtes latins-arabes son exceptionnels dans ces écrits, ou dans les épitaphes latine, telles que celle de «Agoblasto Abeatarecus», soit un Iben Țāriq ${ }^{11}$.

Cependant, si l'on se tourne vers les bien peu nombreux documents en langue arabe qui font mention des chrétiens d'al-Andalus, on voit que certains d'entre eux montrent pour eux des doubles noms, d'un côté latins-germaniques, et de l'autre arabes, comme il en va pour l'évêque Recemundus, autrement appelé Rabī` b. Ziyād ${ }^{12}$, la confusion a été parfois faite entre 'Arīb b. Sa'd (ou b. Sa'îd), l'auteur notamment de la continuation de Tabarī intégrée dans l'édition du Bayān al-Mugirib d'Ibn 'Id dārīi ${ }^{13}$, et ce Rabī' b. Ziyā ${ }^{14}$.

D'autres cas montrent non pas deux noms totalement distincts pour le même individu, comme pour Recemundus/Rabī' b. Ziyād, du moins la combinaison d'éléments arabes et latins. Ainsi, le "comte des chrétiens" (qūmis al-nașārā'), chef de la garde des mercenaires de l'émir alHakam I, Rabī' b. Teodulfto, qui mourut finalement exécuté, portait après un "premier nom" ou prénom arabe (ism 'alam $)^{15}$, Rabī', un nom de filiation latino-chrétien, encore que d'origine

\footnotetext{
7 Alvari Epistula IX, 6, in Corpus Scriptorum Muzarabicorum, éd. Juan Gil, Madrid, Consejo Superior de Investigaciones Científicas, 1973, t. 1, p. 214; Samsonis Apologeticus II. Praefatio 5, in Corpus Scriptorum Muzarabicorum, t. 2, p. 551; Abad Sansón, Apologético, trad. José Palacios Royán, Madrid, Akal, 1999, p. 73.

8 Francisco Javier Simonet, Historia de los mozárabes de España, p. 488. F. Guillén Robles, Málaga musulmana, Malaga, M. Olivier Navarro, 1880, p. 44-45. Cf. Abad Sansón, Apologético, p. 72; texte latin in Corpus Scriptorum Mozarabicorum, t. 2, p. 550.

9 Pedro P. Herrera Roldán, «En torno al mozárabe Cipriano de Córdoba», Exepta Philologica 4-5 (199495), p. 215-229.

10 David Peterson, «The men of wavering faith: on the origins of Arabic personal and place names in the Duero Basin», Journal of Medieval Iberian Studies 3-2 (2011), apendice I, p. 239.

${ }^{11}$ M. Gómez Moreno, Iglesias mozárabes. Arte Español de los siglos IX a XI, Madrid, Centro de Estudios Históricos, 1919, p. 367. Rééd. fac.-sim. avec étude préliminaire d'Isidro Bango Torviso, Grenade, Université de Grenade, 1998.

12 R. Dozy, Le calendrier de Cordoue de l'année 961. Texte arabe et ancienne traduction latine, Leyde, Brill, 1873. Du même Dozy, "Die Cordovaner 'Arīb Ibn Sa'd der Secretär und Rabī‘ Ibn Zeid der Bischof», ZDMG 20 (1866), p. 595-609. Voir aussi Charles Pellat, Le calendrier de Cordoue publié par Dozy. Nouvelle édition accompagnée d'une traduction française, Leyde, Brill, 1961.

${ }^{13}$ Arîb Tabarî Continuatus, éd. M. J. De Goeje, Leyde, Lugd. Bat.- E.J. Brill,, 1897, et trad. espagnole Juan Castilla Brazales, La Crónica de 'Arīb sobre al-Andalus, Grenade, Impredisur, 1992.

14 Ángel Custodio López López, "Vida y obra del famoso polígrafo cordobés del s. X 'Arīb b. Sa'īd», in Ciencias de la naturaleza en al-Andalus, éd. Expiración García Sánchez, t. 1, Grenade, Consejo Superior de Investigaciones Científicas, 1990, p. 317-347, et la version française du même article: «Vie et œuvre du fameux polygraphe de Cordoue 'Arīb b. Sa'îd (Xe siècle)", in Chrétiens, musulmans et juifs dans l'Espagne médiévale, dir. Ron Barkaï, Paris, Éditions du Cerf, 1994, p. 77-101.

15 On évitera évidemment, dans ce contexte, les expressions espagnole «nombre de pila», ou française («nom de baptême»).
} 
germanique (sans doute Theodulf), qui a notablement perturbé les scribes de langue arabe ${ }^{16}$.

L'auteur de la traduction arabe des Psaumes, Hafș b. Albar al-Qūțț ${ }^{17}$, portait, avant son nom de filiation chrétien, bien qu'exprimé en arabe (Ibn Albar, correspondant au castillan ultérieur Álvarez), et sa nisba le rattachant aux Goths, qu'elle fût réelle ou fictive, ou exprimât simplement son appartenance à la population indigène, un nom personnel, Ḥafș, absolument arabe et même islamique, car il avait été porté avant lui, par plusieurs savants musulmans, et, au féminin, par la fille du calife 'Umar b. al-Hațțāb, laquelle se trouvait être au surplus l'une des épouses du Prophète Muhammad lui-même ${ }^{18}$.

Mais on notera que dans ces combinaisons onomastiques c'est bien l'élément arabe qui paraît l'emporter, tant avec le "premier nom" (Rabī', Hafș), que dans la forme, avec la chaine onomastique-généalogique, à une époque où l'usage du nom du père n'est pas encore établi en Occident.

A l'occasion, les écrits de langue arabe ne donnent, pour des personnages évidemment chrétiens, que des noms arabes, ainsi pour l'évêque métropolitain de Tolède (mațrān Țulayțula) 'Ubayd Allāh (ou 'Abd Allāh) b. Qāsim, l'évêque de Cordoue, Așbag̀ b. 'Abd Allāh b. Nabīl, et le cadi des chrétiens de Cordoue, Wālid $b$. Mugìt $\underline{t}^{19}$. On supposera, avec une forte vraisemblance, que ces personnages portaient en même temps des noms chrétiens, que les chroniqueurs arabes ne se soucièrent évidemment pas d'indiquer.

Ainsi la pratique du double nom, latin et arabe, que l'on verra encore mieux documentée dans l'étape léonaise des mozarabes, loin d'être une innovation de cette deuxième période, ou de cette région du Nord péninsulaire, comme il est bien souvent avancé ${ }^{20}$, est-elle tout au contraire une création, apparue dans le contexte d'al-Andalus omeyyade, ensuite, comme on le verra, maintenue et consolidée. Une simple raison de chronologie impose d'inverser la relation le plus souvent admise.

16 Ángel Custodio López López, «El conde de los cristiano Rabī' ben Teodulfo, exactor y jefe de la Guardia Palatina del emir al-Ḥakam I», Al-Andalus-Magreb 7 (1999), p. 169-184. López López relève (note 9, p. 172) le fait qu'aux deux reprises où le personnage apparaît dans le Muqtabis d'Ibn Ḥayyān, le nom de filiation est cité d'une manière qu'il estime incorrecte, et qu'il corrige en "Theodulfo».

17 D. M. Dunlop, "Ḥafș b. Albar: The Last of the Goths?", Journal of the Royal Asiatic Society of Great Britain and Ireland 3-4 (1954), p. 137-151; Marie-Thérèse Urvoy, Le Psautier de Hafs le Goth, Toulouse, Presses Universitaires du Mirail, 1994; Iván Pérez Marinas, «Hafs Ibn Albar al-Qûtî: el traductor mozárabe del Salterio», in Nuevas aportaciones de jóvenes medievalistas. Lleida 2014, ed. Jesus Brufal Sucarrat, Murcia, Compobell S. L., 2014, p. 151-165.

18 Encyclopédie de l'Islam, 2e éd., t. 3, 1965, p. 64-68.

19 F. J. Simonet, Historia de los mozárabes de España, p. 622. R. Dozy, Historia de los musulmanes de España, Madrid, Turner, 1984, t. 3, p. 94. Ces deux auteurs utilisaient, au XIXe siècle, les mêmes textes d'Ibn Haldūn et d'al-Maqqarī. On peut leur ajouter ceux maintenant publiés, notamment le fragment du Muqtabis d'Ibn Ḥayyān traduit par E. García Gómez sous le titre Anales Palatinos del Califa de Córdoba alHakam II (Madrid, Sociedad de Estudios y Publicaciones, 1967), p. 80 et 186. Pour des références plus complètes, J.-P. Molénat, "Chrétiens d'al-Andalus et Omeyyades (VIIle-Xle siècles)", in Al-Andalus Omeya, coord. J. L. Del Pino, Cordoue, Fundación Prasa, 2002, p. 53-65, spécifiquement p. 64, note 35.

20 Ainsi Richard Hitchock voit, curieusement, dans le double nom de Recemundus/Rabī‘ Ibn Zayd l'adoption de la pratique des chrétiens émigrés vers le Nord (Mozarabs in Medieval and Early Modern Spain. Identities and Influences, Aldershot, Ashgate, 2008, p. 48), alors que nous paraît s'imposer à I'inverse la vision du maintien dans le Nord d'une pratique établie dans le contexte d'al-Andalus. De même Gonzalo Carrasco García parle-t-il d'une dualité onomastique qui se constate «a partir del establecimiento de una comunidad mozárabe en tierras cristianas del norte de la Península Ibérica» («La onomástica de la conversión: señas de identidad y transformación antroponímica de los moriscos granadinos, 15001569», Sharq al-Andalus 19 (2008-2010), p. 139-204, spécifiquement p. 146). 


\section{Les "chrétiens arabisés" dans le royaume de León.}

On ne va pas ici s'attarder à relever toutes les occurrences, dans les documents des royaumes chrétiens du nord de la péninsule, et spécialement du León des VIIle-XIle siècles, des noms d'allure arabe, ce travail ayant été très longuement effectué auparavant par d'autres chercheurs ${ }^{21}$.

On discutera seulement deux points. Le premier est la question préalable importante et qui a donné lieu à une discussion qui reste loin d'être tranchée, de la signification et de l'origine de la présence d'une anthroponymie partiellement arabe dans les documents du royaume de León. Le second sera celui, d'apparence plus secondaire, du phénomène du double nom, arabe et roman, déjà mis en évidence en al-Andalus omeyyade, et que l'on retrouvera dans la Tolède chrétienne, principalement du XIle siècle.

La présence d'une population chrétienne peu ou prou "arabisée", au moins en se qui concerne les noms est manifeste dans le nord de la péninsule, et notamment dans le royaume de León, entre le IXe et le XIle siècle, ainsi que l'atteste l'anthroponymie présente dans les documents de cette époque et de ces régions. Il a été énormément, et jusqu'à la satiété, discutée sur l'origine de cette population, et sur celle de son "arabisation", et il faut bien constater que la question reste, à I'heure actuelle, loin d'être résolue d'une manière satisfaisante.

A l'ancienne théorie qu'avait formulée Manuel Gómez Moreno au début du XXe siècle ${ }^{22}$, d'une immigration massive vers le nord de chrétiens fuyant la domination musulmane règnant sur les terres d'al-Andalus, théorie qui s'accordait au mieux avec l'idée si énergiquement défendue par Claudio Sánchez-Albornoz ${ }^{23}$ d'un dépeuplement intégral de la vallée du Duero, que ces mozarabes auraient contribué à repeupler, se sont opposées deux théories nouvelles, en grande partie d'ailleurs contradictoires entre elles. La réfutation de la théorie de Don Claudio s'étant convertie en l'exercice obligé de la génération des médiévistes espagnols apparue depuis la disparition du maître, a entrainé avec elle la contestation, plus ou moins radicale selon les différents auteurs, de celle de l'immigration mozarabe vers le Nord. Pour les uns, une population qui ayant survécue, livrée à elle-même entre les deux dominations asturo-léonaise et araboislamique, se serait arabisée, sans que l'on comprenne pourquoi ni comment, par un mystérieux effet de mode, en l'absence d'une domination arabo-islamique effective dans la plus grande partie de ces régions ${ }^{24}$. Le seul espace où un réel contrôle islamique a pu s'exercer et contribuer à l'arabisation des populations indigènes chrétiennes est constitué par la zone située au nord du

\footnotetext{
21 Victoria Aguilar et Fernando Rodríguez Mediano: «Antroponimia de origen árabe en la documentación leonesa (siglos VIII-XIII)», in El reino de León en la Alta Edad Media, vol. VI, León, Centro de Estudios e Investigación San Isidoro, 1994), p. 497-633. L'un et l'autre de ces deux auteurs ont repris par la suite la question, chacun pour son propre compte: Victoria Aguilar Sebastián, "Onomástica de origen árabe en el reino de León (siglo X)», Al-Qanțara 15/2 (1994), p. 351-363; et Fernando Rodríguez Mediano: «Acerca de la población arabizada del Reino de León (siglos X y XI)», Al-Qanțara 15/2 (1994), p. 465-472. On peut y ajouter notamment les travaux de Cyrille Aillet («Anthroponymie, migrations, frontières: notes sur la 'situation mozarabe' dans le Nord-Ouest ibérique (IXe-Xle siècles)», Annales du Midi 120/26 (2008), p. 532), et ceux de Carlos Reglero de la Fuente ("Onomástica arabizante y migraciones en el reino de León (siglos IX-X)», in Anthroponymie et déplacements dans la Chrétienté médiéval, éd. Monique Bourin et Pascual Martínez Sopena, Madrid, Casa de Velázquez, 2010, p. 89-104).

22 M. Gómez Moreno, Iglesias mozárabes...

23 Despoblación y repoblación del valle del Duero, Buenos Aires, Instituto de Historia de España,1966.

24 L'idée, formulée par Eduardo Manzano Moreno (La frontera de al-Andalus en época de los Omeyas, Consejo Superior de Investigaciones Científicas, Madrid, 1991, p. 161-163 et 172-147) a été fréquemment reprise ensuite, voir par exemple Iñakí Martín Viso («Una comarca periférica en la Edad Media: Sayago, de la autonomía a la dependencia feudal», Studia Historica-Historia Medieval 14 (1996), p. 97-155), qui parle (p. 105-106) de "grupos antónomos que "arabizaron" sus nombres y sus topónimos por influencia de al-Andalus»
} 
Portugal, autour de Coïmbre, reconquise par Almanzor en 988 et demeurée au pouvoir des musulmans jusqu'à la reprise de la ville par les chrétiens léonais en 1064. On relève de fait une forte proportion de noms "arabisés" dans cette région ${ }^{25}$. Pour le reste, on en est réduit à s'appuyer sur le concept, combien flou, de "frontière", qui peut être entendu en bien des sens différents ${ }^{26}$. En tout état de cause, pour ce qui concerne les musulmans, celle de taggr, que l'on veut traduire maintenant par "frontière" plutôt que par "marche", s'applique bien à des territoires situés sous contrôle islamique, pour al-tag்r al-awsaț (la "marche moyenne") et altağr al-adnā (la "marche inférieure"), et non à des espaces situés entre les deux dominations, comme le voudraient les défenseurs de cette "frontière" comme un espace d'arabisation.

Encore plus étrange, s'il est possible, apparaît la théorie, reprise des idées d $\varepsilon$ Jaime Oliver Asín ${ }^{27}$, qui veut voir dans les prétendus mozarabes léonais et castillans les descendants des Berbères mal islamisés, et pas encore arabisés, arrivés dans ces contrées lors de la conquête de la première moitié du VIIle siècle, et qui seraient demeurés sur place ${ }^{28}$, quand on sait que la plus grande partie d'entre eux au moins retournèrent vers le sud au milieu du VIIle siècle. Et l'on ne relève pas chez eux, pas plus que dans la toponymie, de trace d'une onomastique berbère ${ }^{29}$. Et dans l'hypothèse que ces Berbères auraient été, partiellement au moins, de langue latine, on ne comprend pas comment ils auraient laissé une trace arabe tant dans l'anthroponymie que dans la toponymie. Pourtant les Ahbār Mağmū'a, principale source pour l'histoire des événements du milieu du VIIle siècle, laissent effectivement place à la permanence dans le Nord-Ouest de la péninsule, désigné en arabe comme la Ǧillīqiya, d'une population d'abord musulmane, mais qui "douteuse dans sa religion" apostasia et cessa de payer le tribut ${ }^{30}$. Au contraire, selon la

25 Cyrille Aillet, «Anthroponymie, migrations, frontières: notes sur la "situation mozarabe" dans le NordOuest ibérique (IXe-Xle siècle)», Annales du Midi 120/261 (2008), p. 5-32 (spécifiquement p. 7-8).

26 J.-P. Molénat, «Les différentes notions de la frontière dans la région actuelle de Castilla-La Mancha au temps des Almoravides et des Almohades», in Alarcos 1195. Actas del Congreso Internacional conmemorativo del VIII centenario de la batalla de Alarcos (1995. Ciudad Real), coord. R. Izquierdo Benito et F. Ruiz Gómez, Cuenca, Ed. de la Universidad de Castilla-La Mancha, 1996, p. 105-123.

27 En torno a los orígenes de Castilla. Su toponimia en relación con los Arabes y los Beréberes, discours de réception à la Real Academia de la Historia, 24 mai 1974, Madrid, 1974.

28 David Peterson, Fronteras y lenguas en el alto Duero, siglos VIII-XI, Logroño, Instituto de Estudios Riojanos, 2009; Idem, «Aculturación, immigración o invasión: sobre los orígenes de la onomástica árabe en el noroeste peninsular», in Arabes in patria Asturiensium. Asturiensis Regni Territorium 3, éd. Clara Elena Prieto Entrialgo, Oviedo, Universidad de Oviedo, 2011, p. 145-158. Une idée plus ou moins identique est défendue par Javier Fernández Conde, «Poblaciones foráneas: mozárabe, musulmana y judía en el reino de León", in Monarquía y sociedad en el reino de León: de Alfonso III a Alfonso VII (Congreso Internacional León, 25-28 de octubre de 2006), ed. José María Fernández Catón, León, Centro de Estudios e Investigación San Isidoro, 2007, p. 763-89; et "Los mozárabes en el reino de León: siglos VIII-XI», Studia Historica-Historia Medieval 27 (2009), p. 53-69. Cet auteur conclut à l'existence d'un peuplement berbère sur la Meseta du Duero, en n'excluant pas d'autres origines possibles d'une population qui apparaît comme complètement christianisée. Dolores Oliver Pérez, «Documentación leonesa (siglos VIII-XII) y antroponimia árabe», in La península Ibérica al filo del año 1000. Congreso internacional Almanzor y su época (Córdoba, 14-18 de octubre de 2002), éd. José Luis del Pino García, Cordoue, Fundación Prasa, 2008, p. 243-261.

29 A titre d'exemple des contorsions auxquels on s'est livré pour trouver un onomastique berbère dans la documentation léonaise, on prendra la villa «que dicunt Alkamin», située sur le Duero près de Tordesillas («Autero de Sellas»), que donne le roi Alphonse III «secundum nos illut de squalido de gente barbarica manu propria cum pueris nostris adprendimus» (J. M. Mínguez Fernández (éd.), Colección diplomática del monasterio de Sahagún, siglos IX y X, León, Centro de Estudios e Investigación San Isidoro, 1976, doc. 9, p. 37). Il est clair ici que Alkamín n'est pas le nom d'une tribu berbère, par ailleurs inconnue, mais le dérivé du nom du chemin (esp. camino). Eduardo Manzano citait ce toponyme comme d'origine arabe ( $L a$ frontera de al-Andalus en época de los Omeyas, p. 174).

30 Ahbār Mağmū'a, trad. E. Lafuente Alcántara, Madrid, Real Academia de la Historia y Geografía, 1867, p. 49-50: en 123 H/740-741, les Berbères de "Galicia», Astorga, Mérida, Coria et Talavera, soulevés, sont vaincus et massacrés par les Arabes, Syriens et Baladíes, près de Tolède, sur le Guadalete. Puis les Syriens 
Chronique d'Alphonse III, Alphonse I aurait tué tous les "Arabes» (que l'on comprendra plutôt, si l'on veut, comme des Berbères) des cités qu'il occupa et ramené les chrétiens sur ses terres ${ }^{31}$.

En dernier lieu, on trouve la combinaison des deux premières théories, celle de l'immigration mozarabe et celle de l'arabisation in situ, dans un article de Cyrille Aillet qui établit de fines distinctions entre les régions et les moments ${ }^{32}$. À côté de zones, telle que la Galice (au sens actuel), où la présence des noms d'origine arabe ne peut guère s'expliquer que par une immigration en provenance d'al-Andalus, cet auteur maintient la possibilité d'une arabisation sur place de populations indigènes, en situation de frontière.

Il est clair d'un côté que la thèse de Sánchez-Albornoz du dépeuplement intégral, en soulignant ce dernier terme, de la vallée du Duero péchait précisément par son caractère absolu, car aucun espace de la planète, si ce n'est l'Antarctique, ne peut avoir été totalement dépourvu de toute présence humaine, et il sera toujours possible de trouver, même dans les zones les plus "dépeuplées», des traces d'une telle occupation, comme au Sahara. Ainsi l'extrémisme de la position de Sánchez-Albornoz donnait-elle prise à une trop facile réfutation de la part de ses successeurs et adversaires post mortem, encore que le maître ait su nuancer à l'occasion son propos, en admettant la possibilité de la survie de groupes réduits de population gothe dans les sierras centrales de la péninsule ${ }^{33}$, et qu'il convienne donc de prendre chez lui l'affirmation du dépeuplement intégral comme une emphase rhétorique, et non comme la prétention d'une vérité pure et simple.

Mais il est plus douteux qu'il faille totalement abandonner la théorie du "dépeuplement", même relatif, et nier simultanément le "repeuplement" de ces contrées (au sens obvie du terme et non en celui plutôt contourné de l'établissement d'une domination supposément "féodale"), avec notamment l'apport de populations originaires du sud de la péninsule. Cet apport est d'ailleurs attesté, outre la toponymie et l'anthroponymie, par des textes parfaitement clairs, qu'ils soient d'origine asturo-léonaise ou arabo-andalousienne, et donc peu susceptibles de déformation apologétique d'une partie ou de l'autre. Le cas le plus évident est celui de la ville de Zamora, construite, ou plutôt reconstruite, sous l'impulsion du roi de León Alphonse III, en $280 \mathrm{H} / 893-894$, par des gens venus de Tolède, évidemment des chrétiens, selon les historiens les plus autorisés d'al-Andalus, 'T̄sā al-Rāzī, Ibn Ḥayyān et Ibn 'Iḍārīis . Le texte d'Ibn Ḥayyān dit,

poursuivent les Berbères et les tuent «por toda España». Mais il reste des musulmans, que l'on suposera berbères, dans le Nord de la péninsule. (p. 66-67). En $133 \mathrm{H}$, ceux de «Galicia» sont vaincus et chassés (par les chrétiens de Pélage), apostasiant ceux qui étaient douteux dans leur religion et cessant de payer le tribut.

31 Crónicas Asturianas, éd. Juan Gil Fernández et al., Oviedo, Universidad de Oviedo, 1985, texte p. 132133, trad. esp. p. 208-209. Chroniques Asturiennes (fin IXe s.), éd., trad. française et commentaire, Yves Bonnaz, Paris, Centre National de la Recherche Scientifique, 1987, p. 46. Les deux versions de la chronique ne différant ici que par l'ajout, concernant les «Arabes» du membre de phrase: «occupatores supradictorum ciuitatum». II nous paraît clair que les prétendus «Arabes» du royal chroniqueur sont ici bien plutôt des Berbères.

32 Cyrille Aillet, «Anthroponymie, migrations, frontière...».

33 Despoblación y repoblación del valle del Duero, p. 355.

34 Ibn Ḥayyān cite textuellement 'T̄sā al-Rāzī (Muqtabis 3, éd. Melchor Martínez Antuña, Paris, Librairie Orientaliste, 1937, p. 109; éd. I. al-'Arabī, Casablanca, Manšūrāt Dār al- Afāq al-Ğadīda, 1990, p. 131; éd. M. 'A. Makkī, Riyad, Markaz al-Malik Fayșal, 430 H/2009, p. 200; trad. José Guraieb, Cuadernos de Historia de España, Buenos Aires, 13 à 31-32 (1950-1960). Ibn 'Idārī résume (al-Bayān al-Mug̉rib, t. 2, éd. Georges Sérafin Colin et Évariste Lévi-Provençal, Leyde, Brill, 1951, réimp. Beyrouth, Dār al-țaqāfa, 1980, p. 124; trad. Edmond Fagnan, Alger, Imprimerie orientale P. Fontana et cie., 1904, p. 204). Le passage d'Ibn Hayyān a été fréquemment cité, notamment par María Jesús Viguera Molins qui critique la traduction du terme apliqué à Zamora avant sa (re)construction, soit "dépeuplée", et propose "abandonnée", cela ne remettant pas en cause la venue des Tolédans ("En torno a Riba Coa y al-Andalus ", in $O$ Tratado de Alcanices e a importância histórica das terras de Riba Côa (Actas do Congresso histórico luso-espanhol 1217 de Setembro de 1997), Lisbonne, Universidade Católica Ed., 1998, p. 131-152, spécialement p. 140. Voir, plus longuement, J.-P. Molénat, «Le passage des mozarabes d'al-Andalus vers I'Espagne chrétienne», 
en décalquant la traduction de María Jesús Viguera: «'Isā b. Aḥmad rapporte qu'alors Alfonso, fils d'Ordoño, roi de la Ǧilliqiya, marcha sur la ville abandonnée de Zamora et la reconstruisit, I'urbanisa, la fortifia, la peupla de chrétiens et colonisa ses environs. Les reconstructeurs furent des gens de Tolède, grâce à l'un de leurs chrétiens». II nous paraît tout à fait significatif que ce soit précisément dans les documents correspondant à la zone de Zamora que l'on trouve, au Xe siècle, la plus forte proportion de noms d'origine arabe ${ }^{35}$, les chroniqueurs arabes et les scribes des documents chrétiens se corroborant ainsi réciproquement.

Fernando Rodríguez Mediano a cru qu'il existait une contradiction entre le supposé apport de chrétiens "mozarabes" fuyant la domination musulmane en al-Andalus vers les terres chrétiennes du royaume de León, et la permanence, sur ces mêmes terres, chez une population "mozarabe", d'une anthroponymie partiellement d'origine arabe ${ }^{36}$. C'est là ne pas apercevoir la distinction qu'il convient d'établir, entre la domination musulmane, avec notamment l'application en al-Andalus des règles discriminatoires de la dimma, auxquelles les "chrétiens arabisés" ont pu vouloir effectivement échapper en venant s'installer dans le Nord de la péninsule, et l'arabisation culturelle, au moins au niveau linguistique, qui nous apparaît à travers l'onomastique, et qui fait des "chrétiens arabisés" véritablement, et pour la première fois dans le plein sens du terme, des "mozarabes" (musta'riba) ${ }^{37}$, lorsqu'ils se retrouvent au milieu de chrétiens de langue romane.

On a pu montrer ailleurs que ce terme de "mozarabe", loin d'être primitivement péjoratif, comme voudra le suggérer, au XIIle siècle l'archevêque Rodrigo Jiménez de Rada, lorqu'il l'expliquera comme "mixti arabes»" ${ }^{38}$, était laudatif et revendiqué par les intéressés eux-mêmes ainsi qu'il apparaît dans le fuero de 1101 donné par Alphonse VI «à tous les mozarabes de Tolède», dit-il, "que j'ai toujours aimés, et ramenés dans cette ville de terres étrangères pour peuplers ${ }^{39}$.

II ne paraît pas juste de parler d'une onomastique "arabisante" 40 ou "arabisée" 41

in Passages. Déplacements des hommes, circulation des textes et identités dans l'Occident médiéval, éd. Joëlle Ducos et Patrick Henriet. Actes du colloque de Bordeaux (2-3 février 2007), Toulouse, Méridiennes, 2013, p. 67-76.

${ }^{35}$ C. Reglero de la Fuente («Onomástica arabizante y migraciones en el reino de León», p. 98): 30 \% sur 100 noms.

36 "Acerca de la población arabizada del Reino de León (siglos X y XI)", Al-Qanțara 15/2 (1994), p. 465472.

37 Dominique Urvoy a montré que le terme musta'rib, étymon arabe évident de "mozarabe" n'était jamais employé pour les chrétiens d'al-Andalus, et qu'au contraire en Orient il était employé par des chrétiens arabes, convertis à l'Islam, et revendiquant leur arabité («Les aspects symboliques du vocable "Mozarabes", essai de réinterprétation», Studia Islamica 78 (1993), p. 117-153).

38 Historia de rebus Hispanie sive Historia Gotica, Libro III, cap. 22, éd. Juan Fernández Valverde, Turnhout, Brepols, 1987, p. 107: "et isti dicti sunt mixti Arabes, eo quod mixti Arabibus convivebant, quorum hodie apud nos nomen perseuerat et genus». Historia de los hechos de España, trad. Juan Fernández Valverde, Madrid, Alianza Editorial, 1989, p 152: «y a éstos se les dio el nombre de "mozárabes", porque vivían mezclados con los árabes, cuyo nombre y linaje subiste aún hoy entre nosotros».

39 "facio hanc cartam firmitatis ad totos Muztarabes de Toleto... ut vos omnes quos in hac urbe semper amavi et dilexi, seu de alienis terris ad populandum adduxi, semper habeam fideles et oratores" (Tomás Muñoz y Romero, Colección de fueros municipales y cartas pueblas, Madrid, Real Academia de Historia, 1847, réimp. Madrid, 1972, p 360; A. García-Gallo, "Fueros de Toledo», Anuario de Historia del Derecho Español 45 (1975), p. 421, et ap. 1, p. 460; Ángel González Palencia, Los Mozárabes de Toledo..., MT-VP, p. 119 , avec des variations sur la graphie du terme corresppondant à «mozarabes», selon les copies utilisées.

40 Carlos Reglero de la Fuente parle par exemple d'une «onomástica arabizante».

41 Gonzalo Martínez Díez, tout en mentionnant le double nom des mozarabes de León, écrit à propos de ces noms "uno cristiano y otro arabizado», maintenant ainsi en outre la confusion entre le religieux et le linguistique («La emigración mozárabe al reino de León, siglos IX y X», Mozárabes, identidad y 
s'agissant des mozarabes du royaume de León. Il serait plus exact de dire "onomastique arabe romanisée", car c'était bien des noms arabes que portaient un grand nombre des individus en question, mais transcrits en caractères latins, avec l'approximation dont étaient capables les scribes léonais, évidemment pas arabophones pour ce qui les concernait ${ }^{42}$. L'approximation se situe tant au niveau acoustique, avec l'incapacité pour qui n'est pas arabophone d'entendre et d'articuler certains sons de la langue arabe, notament le 'ayn, qu'au niveau scripturaire, avec la difficulté à les rendre en caractères latins, les scribes romans du haut Moyen Âge ne disposant évidemment pas des systèmes de diacritiques élaborés par les orientalistes modernes, ces derniers étant au surplus incapables de se mettre d'accord entre eux, suivant les pays ou les langues européennes dans lesquelles ils écrivent, et s'obstinant à donner des approximations correspondant à leur propre langue, tout come le faisaient les scribes du León.

Pour ce qui est du double nom, arabe et latin, les références ne son pas nombreuses, mais elles existent. Ainsi, on trouve en 959 , le prêtre Melic "qui de babtismo Saluti uocatur» ${ }^{43}$, et qui signe, l'année suivante, comme «Salute, cognomento Melic, presbiter» ${ }^{44}(I, 167)^{45}$, et, encore en 959 fait une donation comme "ego Saluti presbitero cognomento Meliki» ${ }^{46}$. On ne peut pas imaginer un musulman dénommé Malik qui, converti, aurait reçu Salute comme nom de baptême ${ }^{47}$, hypothèse infirmée par la première dénomination : comment aurait-il été désigné par son nom de musulman tout en le disant «presbiter»? Bien plutôt, le cognomen est ici le nom arabe d'un personnage pourvu d'un double nom arabe et latin. Par ailleurs, les nombreux documents où il est seulement désigné comme "Melic presbiter», ou même uniquement «ego Melichi» ${ }^{48}$, laissent suspecter que le phénomène du double nom était bien plus répandu que les rares cas où il est explicité.

Ainsi peut-on expliquer que dans le document de 1024, avec lequel fait son apparition le vocable de "mozarabes» ${ }^{49}$, un seulement des trois individus auxquels il s'applique soient désignés par un nom d'origine arabe: «muzaraues de rex tiraceros nominatis Uincente et Abiahia et loannes». Sans doute le dit «Abiahia» (soit Abū Yahyāa) avait-il également un nom chrétien, qui n'est pas indiqué, comme les deux autres pouvaient posséder des noms arabes, ignorés par le scribe, probablement parce qu'ils ne les donnaient pas eux-mêmes.

Les cas sont relativement nombreux, où le cognomen apparaît comme le nom arabe d'un personnage précédemment désigné par un nom latin. On ainsi, en 912, "Recemirus, cognomenta Abolfetae ${ }^{50}$. Ce dernier nom, peut-être une kunya pour Abū al-Fath, se retrouve à diverses reprises comme "Abulpheta Iben December», ou «Abolfeta Iben December» en 918

contininuidad de su historia, Antigüedad y cristianismo 28 (2011) [éd. 2013], p. 99-117, spécifiquement p. 107).

42 V. Aguilar Sebastián et F. Rodríguez Mediano relèvent les variations auxquelles peut donner lieu, en latin, la transcription d'un même nom arabe, ainsi pour Qāsim, et les composés de 'Abd («Antroponimia de origen árabe, p. 511).

43 E. Sáez et C. Sáez (eds.), Colección documental del Archivo de la Catedral de León, t. 2, León, Archivo Histórico Diocesano, 1990, doc. 321, p. 97-98.

44 E. Sáez et C. Sáez (eds.), Colección documental..., doc. 328, p. 106-107.

45 V. Aguilar Sebastián et F. Rodríguez Mediano, «Antroponimia de origen árabe, p. 595, note 179.

46 J. M. Mínguez Fernández (ed.), Colección diplomática del monasterio de Sahagún (siglos IX y X), León, Centro de Estudios e Investigación San Isidoro, 1976, doc. 167, p. 207-208.

47 J. Fernández Conde, «Los mozárabes en el reino de León», p. 68, pour un homme de «nombre cristiano y sobrenombre árabe», "quizás porque hubiera recibido el bautismo o casado con muger cristiana».

48 J. M. Mínguez Fernández (éd.), Colección diplomático del monasterio de Sahagún, docs. 69, 75, 81, 90, $103,109,111,121,125,131,133,167,168,183$, même si l'éditeur exprime ses doutes sur l'authenticité de certains d'entre eux (ibid. p. 229).

49 J. M. Ruiz Asencio (éd.), Colección documental del Archivo de la Catedral de León, t. 3, León, 1987, doc. 806, p. 399-400, avec au bas du document les signa: "Muzarauis: Uincentius, loannes, Abiahia».

50 E. Sáez et C. Sáez (eds.), Colección documental del Archivo de la Catedral de León, t. 1, doc. 27, p. 44. 
et $925^{51}$, mais également son fils, "December filius de Abolfeta», en 923. Le fait que ce dernier soit témoin en même temps que "Recemirus qui et Abolfeta» ${ }^{52}$, empêche de l'identifier à lui, mais il est assez vraisemblable qu'il s'agisse bien du père et du fils. Le mélange des noms arabes et romans dans la même famille paraît caractérisque, et loin que nous puissions dire que cette oscillation onomastique rende difficile d'inscrire ces personnages à une communauté mozarabe, les variations empêchant de déterminer qui l'était et qui ne l'était pas ${ }^{53}$, on soutiendra bien plutôt tout au contraire que ce sont précisément ces variations qui sont caractéristiques des chrétiens arabisés, mozarabes si l'on veut conserver le terme traditionnel.

\section{Dans la Tolède des XIle et XIIle siècle.}

Alors que dans le León des IXe-Xle, les chrétiens arabisés, que I'on peut désormais, sans contestation, qualifier de "mozarabes", puisque le terme apparaît avec eux et à leur époque, n'ont pas laissé, en dehors des notes marginales de certains manuscrits ${ }^{54}$, trace d'une pratique de l'écriture arabe, celle-ci se manifeste pleinement dans la Tolède des XIle et XIIle siècle, avec les quelque 1200 documents arabes tolédans qui sont parvenus jusqu'à nous, et ont été en grande partie édités et traduits dans la première moitié du XXe siècle, puisque outre les documents qui ont déja fait l'objet d'une édition et publication, et dont le nombre s'élève bien à 1200 , en y incluant les documents juifs, on sait qu'il en reste une nombre indéterminé, probablement assez limité, encore inédits dans les archives tolédanes, principalement ecclésiastiques.

Selon toute apparence, l'arabisation des dénommés mozarabes tolédans était, au moins dans une première période, plus profonde que ne l'avait été celle de leur prédécesseurs dans les zones septentrionales de la péninsule, la plus grande profondeur de leur arabisation s'expliquant par une séjour plus prolongé à l'intérieur de la dār al-islām d'al-Andalus, jusqu'à la conquête de Tolède par Alphonse VI (1085), ou leur émigration vers les rives du Tage, au milieu du XIle siècle.

Non seulement les chrétiens arabisés de Tolède étaient capables d'élaborer leurs propres documents, écrits en langue et écriture arabes et suivant les formules de la pratique notariale arabe et islamique, même si le contenu en restais celui de la loi wisigothique ${ }^{55}$, mais encore ils se montrèrent à même, au moins durant le Xlle siècle, d'assimiler les nouveaux venus arrivés sur les rives du Tage depuis les contrées situées au Nord des Pyrénées, ce qui a permis de parler d'une «mozarabisation des Francs $»^{56}$.

Après 1085 , la dualité de noms des mozarabes a perduré un certain temps, qui s'est étendu au moins jusqu'au début du XIIle siècle, dans la Tolède passée au pouvoir des chrétiens du nord de la péninsule, mais qui constituait désormais également désormais le principal et ultime foyer

51 E. Sáez et C. Sáez (eds.), Colección documental del Archivo de la Catedral de León, t. 1, doc. 48, p. 78; doc. 68, p. 116.

52 E. Sáez et C. Sáez (eds.), Colección documental del Archivo de la Catedral de León, t. 1, doc. 58, p. 98.

53 V. Aguilar Sebastián et F. Rodríguez Mediano, "Antroponimia de origen árabe...», p. 543.

54 Cyrille Aillet, «Las glosas como fuente para la historia del cristianismo arabizado en la Península Ibérica (siglos IX-XIII)", in Relegados al margen. Marginalidad y espacios marginales en la cultura medieval, éd. Inés Monteira Arias et al., Madrid, Consejo Superior de Investigaciones Científicas (Biblioteca de Historia del Arte), 2009, p. 19-29.

55 J.-P. Molénat, «Peut-on trouver trace de la Loi islamique dans les documents arabes chrétiens de Tolède des XIIe et XIIle siècles?», communication au colloque international tenu, sous la direction de Christian Müller, au Centre Jacques Berque de Rabat (Maroc), les 13-15 novembre 2013: "Rethinking Classical Islamic Law: Can Fiqh be Aplied Law?», publiée dans Medievalista on-Line 20 (2016), avec la regrettable coquille faisant de Ferdinand VI, au lieu d'Alphonse VI, le conquérant de Tolède en 1085.

56 J.-P. Molénat, "Les Francs de Tolède aux XIle et XIIle siècle à travers les documents de la pratique», Comprendre le XIIle siècle. Études offertes à Marie-Thérèse Lorcin, dir. P. Guichard et D. Alexandre-Bidon, Lyon, Presses Universitaires de Lyon, 1995, p. 59-72. 
mozarabe ${ }^{57}$, là où étaient venu confluer, au milieu du XIle siècle, les chrétiens arabisés demeurés jusque là dans le Sud de la péninsule avec ceux restés sur place durant la domination islamique, ou déjà arrivés au temps d'Alphonse VI.

Cette dualité de noms est clairement explicitée, dans un document de 1115, écrit en langue latine et suivant le formulaire en usage dans le nord de la péninsule, disant:

«In Dei nomine ego Dominico Petriz, qui ita uocor in latinitate et in algarauia Auolfaçan Auenbaço, similiter et ego Dominiquiz, qui ita uocor en latinitate et in algarauia Aulfacam Auencelema, una pariter cum uxores nostras Columba et Leocadia, uendimus una uinea que habemus... ${ }^{58}$.

On comprendra par là que Domingo Pérez s'apelait en arabe Abū I-Ḥasan Ibn Basuh et que $X$. Domínguez se nommait également Abū I-Ḥasan Ibn Salama, tandis que leurs épouses respectives semblent n'avoir eu que des noms latino-chrétiens. L'autre fait notable est que dans les noms arabes des deux contractants masculins apparaît une kunya, élément théoriquement correspondant au nom du fils ainé, mais souvent simplement une désignation honorifique, alors que celle-ci, du moins en Orient, se voyait exclusivement attribuée à des musulmans ${ }^{59}$. On pourra donc voir dans l'adoption d'une kunya par les chrétiens arabisés de Tolède, comme chez leurs prédécesseurs du royaume de León, l'expression de leur libération des restrictions auxquelles ils avaient été, théoriquement au moins, soumis antérieurement durant leur séjour sous le règne de la šarĩa.

Un cas particulier est représenté, en 1129, par le représentant le plus élevé des mozarabes tolédans, l'alguacil-alcalde qui apparaît sous des noms différents dans le même document ${ }^{60}$. En premier lieu, il est mentionné comme al-wazīr al-qāọi Abū l-Așbag̉ b. Lanbažār, (avec la flexion du mot "Abū» grammaticalement exigée), puis seulement comme ledit alguacil-alcalde, et enfin il signe: «Et moi, 'Abd al-'Azīz b. Lanbazāar, j'ai vu cela» («wa-anā 'Abd al- 'Azīz b. Lanbaz̦ār raytu dālik»). La kunya révérentielle est tout d'abord utilisée comme telle ${ }^{61}$ lorsque l'on parle de lui, mais il signe lui-même de son ism 'alam. On pourrait penser, bien que son nom roman ne figure pas dans ce document, qu'il s'identifie avec le personnage assez bien connu dans I'histoire, sous celui de Melendus Aben Lampader, alcalde de Tolède pour les mozarabes, dans la seconde moitié du XIle siècle, mentionné comme "Melendus Aven Lampade» ou "Melendo Elampade», alguacil "çafalmedina in Toledo» en $1152^{62}$, confirmant des documents royaux entre 1166 et $1179^{63}$, et que le même homme portait deux noms personnels différents en langue latine (Melendus) et en arabe ('Abd al-Azīz). En fait cette identification se heurte en tout premier lieu

57 Ramón Gonzálvez, «Toledo, último reducto del mundo mozárabe», in Los Mozárabes. Una minoría olvidada, éd. Manuel González Jiménez et Juan del Río Martín, Séville, Fundación El Monte, 1998, p. 4786.

58 Ángel González Palencia, Los Mozárabes de Toledo en los siglos XII y XIII, MT-VP, p. 123. Francisco Javier Hernández, Los cartularios de Toledo. Catálogo documental, Madrid, Fundación Ramon Areces, 1985, doc. 19, p. 19-20; Archivo Histórico Nacional, Cod. 996 B, f $99 r^{\circ}$.

59 Jacqueline Sublet, Le voile du nom. Essai sur le nom propre arabe, Paris, PUF, 1991; Ignaz Goldziher, "Der Gebauch der Kunja als Ehrenbezeigung», Muhammedanische Studien, New York, University of New York Press, 1971, t. 1, p. 267 (trad. française G. H. Bousquet, Arabica 8/2 (1960), p. 113-114); María José Cervera Fras, «El nombre propio árabe medieval. Sus elementos, forma y significado», Aragón en la Edad Media 9 (1991), p. 225-240, spécialement p. 233-234.

60 Ángel González Palencia, Los Mozárabes de Toledo..., MT 1012.

61 Et non pas comme un ism 'alam, ainsi qu'on a voulu le voir pour les mozarabes léonais.

62 José Luis Martín, Orígenes de la Orden militar de Santiago, Barcelone, CSIC, 1974, docs. 17 et 18.

63 Julio González, El reino de Castilla en la época de Alfonso VIII, 3 vol., Madrid, CSIC, 1960. Index, t. 3, p. 932, avec notamment les documents 215, 29 janvier 1175, confirmé par Petrus Didaci et Melendus Lampader "alcaldes Toleti», et 324, 30 avril 1179, avec confirmation de "Melendus Lampaer, alcallus Toleti de mozarabis». 
à une sérieuse difficulté chronologique, car il est difficile de penser que le personnage, déjà investi d'une charge importante en 1129, restait dans l'exercice de la même fonction exactement un demi siècle plus tard. En fait l'alcalde Aben Lampader de la seconde moitié du siècle du XIle siècle, était le fils d'Abū al-Așbag 'Abd al-'Azīz, exerçant la même fonction que son père, ainsi que le révèle en 1207 , après son décès, deux documents qui lui donnent son nom arabe sans doute presque complet, manquant encore une kunya, dans la supposition qu'il en possédait une comme son père, et le désignant comme le défunt alcalde don Melendo b. 'Abd al-'Azīz b. Lanbaz̄ārón.

Si donc le double nom, arabe et roman, des mozarabes tolédans n'apparaît pas directement dans le cas des Beni Lampader, le père et le fils, mais plutôt, semble-t-il, le passage d'un nom purement arabe dans la première moitié du XIle siècle pour le père, à une formule mixte, formée d'éléments arabes et romans, au moins dans les documents arabes, pour le fils, dans la seconde moitié du même siècle, ce double nom est pleinement attesté dans d'autres documents arabes, où il s'agit d'établir clairement l'identité de personnages moins illustres que les chefs de la communauté chrétienne arabisée de Tolède, des hommes qui apparaissent seulement, dans la plupart des cas, à titre de témoins.

En 1174, néanmoins, c'est encore un notable, l'alguacil-almojarife (al-wazìr al-mušrif), en charge vraisemblablement des affaires financières de la ville, plutôt que des finances royales, don Domingo b. Sulaymān b. Ġașn b. Širband qui vend une maison et signe «Moi Hālid b. Sulaymān b. Ġașn b. Širband lesusdit j'ai témoigné pour moi-même.... $\rangle^{65}$. Ici on a clairement une alternance du prénom chrétien roman (Domingo) et de l'ism 'alam arabe (Khaled en version française courante), si le reste de la chaine onomastique reste identique. Dans le courant du XIII siècle, si l'on peut suivre la continuité de cette famile, dont les noms apparaissent à l'occasion encore en arabe, le ism 'alam arabe n'est plus mentionné. On a ainsi en 1243, don Servand, alcalde de la cour du roi, fils de l'alguacil-almojarife don Domingo b. Servand (al-wazìr al-qāộ̄ al-ağall dūn Širband qāḍi haḍrat man ayyada-hu Allāh wa-nașara-hu wa ibn al-wazīr al-mušrif dūn Duminquh b. Širband) ${ }^{66}$.

La même alternance du prénom chrétien et de l'ism 'alam arabe est mise évidence en 1177 avec Yuwān b. 'Umar, qui «est Șālih, de l'église de Šant Lūqa», où, curieusement dans la première formulation le prénom chrétien est suivi d'un «nom du père» arabe et musulman, tandis que dans la seconde, le nom arabe est accolé à une désignation toponymique évidemment chrétienne, correspondant à l'une des paroisses dites mozarabes de la ville ${ }^{67}$. On ne sera donc pas tenté de voir dans la première formule l'expression de la conversion au christianisme du fils d'un père musulman, mais bien plutôt dans l'une et l'autre celles d'une double identité, déclinée de façons inverses, mais également pertinentes.

On peut donner d'autres exemples, encore dans les premières années du XIIle siècle. En 1207, Pedro b. Juan b. Wālid b. Qāsim est témoin en même temps que celui qui n'est autre, selon toute vraisemblance, que son père, Yahyā b. Wālid b. Qāsim. En ce cas, si l'on n'a pour le fils que le nom latin-chrétien Pedro (Bītruh), il apparaît que en ce qui concerne le père alternait pour le même nom, correspondant à Jean, la forme arabe (Yahyyā) et celle, romane, plutôt que latine (Yuwān $)^{68}$.

Mais parfois également, il n'existe aucune correspondance qui permettrait d'identifier les noms du même personnage fournis sous les formes arabe et latine, si cette équivalence ne se

64 Ángel González Palencia, Los Mozárabes de Toledo..., MT 355 et 1075.

65 Ángel González Palencia, Los Mozárabes de Toledo..., MT 109.

66 J.-P. Molénat, «L'identité mozarabe dans I'Ibérie reconquise, spécialement à Tolède», dans H. Bresc et C. Veauvy (dir.), Mutations d'identités en Méditerranée. Moyen Âge et Époque contemporaine, Paris, Éd. Bouchene, 2000, p. 123-131, avec un paragraphe: "Deux familles mozarabes de Tolède au service de la construction de l'État castillan: les Banû Shirband et les Banū Wazlân».

67 Ángel González Palencia, Los Mozárabes de Toledo..., MT 134.

68 Ángel González Palencia, Los Mozárabes de Toledo..., MT 359. 
trouvait pas spécifiée dans le document lui-même. Ainsi, en 1193, "Ego Clemens lohannis testis», signant ainsi, est identifié au pied du document comme "lbn 'Abd al-'Azīz al-Ḥamāmī» ${ }^{69}$.

\section{Pour conclure.}

Notre conclusion est donc que le double nom des chrétiens arabisés de la péninsule ibérique est une réalité qui perdure depuis le début de l'arabisation des indigènes placés sous la domination musulmane dans la partie méridionale de l'ancienne Hispania, jusqu'à son extinction dans son dernier réduit, la Tolède du XIle, et, partiellement au moins, du XIIle siècle. Une dualité qui apparaît comme indissociable de leur identité de "mozarabes», apparue dans les conditions d'al-Andalus omeyyade et qui a pu perdurer et s'affirmer longtemps dans celles de la prétendue "Reconquête", jusqu'à finalement s'effacer devant celle-ci.

69 Ángel González Palencia, Los Mozárabes de Toledo..., MT 233. 